University of Nebraska - Lincoln

DigitalCommons@University of Nebraska - Lincoln

USDA National Wildlife Research Center - Staff Publications
U.S. Department of Agriculture: Animal and Plant Health Inspection Service

April 1998

\title{
A review of the case histories of the brown tree snakes (Boiga irregularis) located by detector dogs on Guam
}

Richard M. Engeman

USDA-APHIS-Wildlife Services, s_r100@yahoo.com

Danny V. Rodriguez

USDA/APHIS/ADC

Michael A. Linnell

USDA/APHIS/ADC

Mikel E. Pitzler

USDA/APHIS/ADC

Follow this and additional works at: https://digitalcommons.unl.edu/icwdm_usdanwrc

Part of the Environmental Sciences Commons

Engeman, Richard M.; Rodriguez, Danny V.; Linnell, Michael A.; and Pitzler, Mikel E., "A review of the case histories of the brown tree snakes (Boiga irregularis) located by detector dogs on Guam" (1998). USDA National Wildlife Research Center - Staff Publications. 634.

https://digitalcommons.unl.edu/icwdm_usdanwrc/634

This Article is brought to you for free and open access by the U.S. Department of Agriculture: Animal and Plant Health Inspection Service at DigitalCommons@University of Nebraska - Lincoln. It has been accepted for inclusion in USDA National Wildlife Research Center - Staff Publications by an authorized administrator of DigitalCommons@University of Nebraska - Lincoln. 


\title{
A review of the case histories of the brown tree snakes (Boiga irregularis) located by detector dogs on Guam
}

\author{
Richard M. Engeman ${ }^{\mathrm{a} . *}$, Danny V. Rodriquez ${ }^{\mathrm{b}}$, Michael A. Linnell ${ }^{\mathrm{b}}$, Mikel E. Pitzler ${ }^{\mathrm{b}}$ \\ ${ }^{a}$ National Wildlife Research Center. 1917 Heath Parkway, Fon Collins. CO 80524-2719. LSA \\ ${ }^{h}$ USDA APIIS ADC, 1060 Route 16. Suite 103-C', Barrigada Heights, GU 96921, USA
}

Accepted 29 January 1998

\begin{abstract}
Records of 34 brown tree snakes detected during dog inspections were examined to describe the situations in which snakes were found and to determine probable destinations had they successfully departed Guam. A key to the use of detector dogs for interdicting brown tree snake transport from Guam is that the snakes found are at high risk for export. Hawaii, followed by the Micronesian islands, were the most frequently identified potential destinations for the snakes located by dogs. Published by Elsevier Science Ltd.
\end{abstract}

\section{Introduction}

The brown tree snake, Boiga irregularis, is an exotic species that was inadvertently introduced to the island of Guam, probably in the 1940s (e.g., Fritts, 1988; Rodda et al., 1992). Since then, it has been responsible for the extirpation of. or substantial reductions in populations of Guam's forest birds (Savidge, 1987), fruit bats (Wiles, 1987a, 1987b: Wiles et al., 1995), and native lizard species (Rodda and Fritts, 1992). It has also become a problem for local poultry producers (Fritts and McCoid. 1991), electrical utilities (Fritts et al., 1987) and is a public health and safety risk (Fritts et al., 1990).

Guam's importance as a shipping hub in the Pacific, coupled with the fragility of other Pacific island ecosystems to which much of the out-going cargo flows, has made the potential spread of the brown tree snake from Guam a serious concern. Between 1949 and 1996, brown tree snakes have been recovered on Oahu in the state of Hawaii; Saipan, Tinian and Rota in the Commonwealth of the Northern Marianas (CNMI); Pohnpei in the Federated States of Micronesia (FSM); Kwajalein in the Marshall Islands; Diego Garcia Atoll in the Indian Ocean; Okinawa in the Ryukyu Islands of Japan; Cocos Island of Guam; Wake Island; south Texas (Fritts, 1987; McCoid and Stinson, 1991; McCoid et al., 1994 unpublished summary from workshop on Controlling the Brown Tree Snake and Preventing its Colonization of Micronesia). No documentation to date confirms that

\footnotetext{
*Corresponding author.
}

brown tree snakes have established breeding populations at any of these locations, however a large number of sightings on Saipan have led to speculation that an incipient population exists there (McCoid et al., 1994).

Operational control and containment activities were initiated in 1993 on Guam at air and sea port facilities, and other areas of high risk, to curtail the dispersal of the snakes from Guam. Much of the control effort has been directed at the capture of brown tree snakes from the high risk areas by a variety of trapping strategies and during night searches of fence lines using spotlights. However, much of the cargo exported from Guam originates from areas of the island outside where snake removal efforts are applied. A large portion of the cargo flow from Guam has been defined and categorized according to the threat of dispersing brown tree snakes to vulnerable destinations (Linnell and Pitzler. 1996). Cargo destined for susceptible locations and the associated cargo holding facilities are subjected to searches for snakes using detector dogs. Long-term investigations are currently underway to examine the efficacy of the detector dogs for locating brown tree snakes in a variety of operational circumstances. As a preliminary to the eventual results from controlled trials, we report here on the case histories to date of the naturally occurring brown tree snakes located by the dogs and their most likely destinations had they successfully been transported from Guam.

\section{Materials and methods}

Cargo, cargo staging areas, and transport vessels identified as posing a risk for accidental introduction of a 
brown tree snake to a vulnerable location are subjected to searches by detector-dog teams of the USDA APHIS Animal Damage Control (ADC) operational staff on Guam. Each team is comprised of a handler and the unique detector-dog (Jack Russell terrier) assigned to that handler. Table 1 provides an overview of the general locations. materials and frequency of inspections using dogs. During an inspection. the dogs have the stamina to search for 40-60 min. depending on temperature and the physical difficulty of the search.

Records of dog search activities have been maintained by ADC on Guam and the records of all cases where brown tree snakes were located by the detector dog teams were examined for the present study. The data contained in the records included the specific dog and handler, the date, the time. the location searched and the details of exactly where the snake was found at that location. The records date from the initial use of the detector dogs in 1993. Based on where each snake was found and the cargo or vessel movements associated with that location at that time, we identified the most likely possible destinations for each snake had it successfully departed Guam.

\section{Results}

Table 2 summarizes the data for the 34 brown tree snakes located through August 1996 by detector dogs. The detail in Table 2 also provides an indication of the diversity of materials and ever-changing situations to which the detector dog teams are applied and in which brown tree snakes have been found during operational searches.

Some difficulty exists in relating where the snakes have been found (Table 2) to where dog team inspections currently take place (Table 1 ). In some cases, search sites have changed possession, such as the Naval Air Station which is no longer a military installation but is under the Guam Airport Authority at Won Pat International Airport. Also, there can be no clear distinction for categorizing a snake located during a military exercise and a snake located on a military base when the base is being used in a military exercise. Operationally, the increase in activity during an exercise results in increased use of dog teams for inspections. Other ambiguities exist between where snakes have been found and the categories for inspections in Table 1. We therefore do not attempt to

Table 1

An overview of locations. types. and frequencies of brown tree snake inspections condueted with detector dog teams on Guam'

\begin{tabular}{|c|c|c|}
\hline Location ${ }^{2 . ;}$ & Frequency. & Inspection description ${ }^{2}$ \\
\hline AAFB warehouses & Daily & $\begin{array}{l}\text { Outbound cargo and the cargo staging areas (indoors and outdoors) are inspected at the } \\
\text { AMCC, TMO and HC-5 warehouses. }\end{array}$ \\
\hline$A A F B$ aircraft & By request & $\begin{array}{l}\text { Cargo and aircraft are inspected when a plane has remained over night and a request is } \\
\text { made for an inspection. }\end{array}$ \\
\hline Harmon industrial & Daily & Outbound cargo and the staging area vicinity inside up to 7 warchouses. \\
\hline NAVACTS warchouse & When ship loads & $\begin{array}{l}\text { Cargo and staging areas of FISC warehouse are inspected as ship is loading, often } \\
\text { requires multiple inspections per day. }\end{array}$ \\
\hline NAVACTS Kilo Wharf & When ship loads & Ordnance is inspected prior to loading ship. \\
\hline NAVACTS Polaris Point wharf & $\mathrm{NA}$ & $\begin{array}{l}\text { Wharf area formerly was inspected. but discontinued because ships were using it for } \\
\text { staging areat, not transfer of cargo. }\end{array}$ \\
\hline Apra Harbor Commercial Port & Daily & $\begin{array}{l}\text { Inspections are made of outbound cargo and cargo staging areas at } 2 \text { warehouses. break- } \\
\text { bulk cargo. and boats and barges that transport cargo. }\end{array}$ \\
\hline Apra Harbor Hotel Wharf & Daily & Break-bulk cargo and boats and barges are inspected. \\
\hline WPIA cargo & Daily & $\begin{array}{l}\text { Cargo and cargo staging areas, inside and outside, are inspected for commercial airlines } \\
\text { with destinations vulnerable to snake introduction. Commuter and private areas are not } \\
\text { inspected at this time. }\end{array}$ \\
\hline Military exercises & As occur & $\begin{array}{l}\text { Dog teams are on } 24 \text { hour call to inspect cargo. staging areals. vehicles. transportation } \\
\text { craft and personal gear associated with military exercises. }\end{array}$ \\
\hline Military housing & Daily & $\begin{array}{l}\text { Goods in household moves are inspected the same day they are loaded for shipment off- } \\
\text { istand. Inspections occur at AAFB. AAFB-South. NCTAMS. NAVACTS. Nimitz. Hill, } \\
\text { Naval Hospital. }\end{array}$ \\
\hline Civilian housing & Daily & $\begin{array}{l}\text { Civilians under military contract. subject to moves by the military are inspected in the } \\
\text { same fashion as military housing. Location can be anywhere on Guam. }\end{array}$ \\
\hline Sllake sightings & By request & Searches are sometimes conducted in housing to track a snake that had been sighted. \\
\hline
\end{tabular}

\footnotetext{
'Inspection sites as of August 1996. except for Polaris Point Wharf where inspections were discontinued.

$\mathrm{AAFB}=$ Andersen Air Force Base. $\mathrm{AMCC}=$ Air Mobility Control Center, FISC $=$ Fleet Industrial and Supply Center. HC $-5=$ helicopter squadron warchouse, NAVACTS $=$ Naval Activities, NCTAMS $=$ Naval Computer and Telecommunications Area Master Station. TMO $=$ Traffic Management Operations. WPIA = Won Pat International Airport.

${ }^{3}$ Areas and frequency have increased as dog-teams have been added to the program.
} 
Table 2

Summary of brown tree snakes found in inspections by detector dogs and their most likely destinations had they departed Guam.

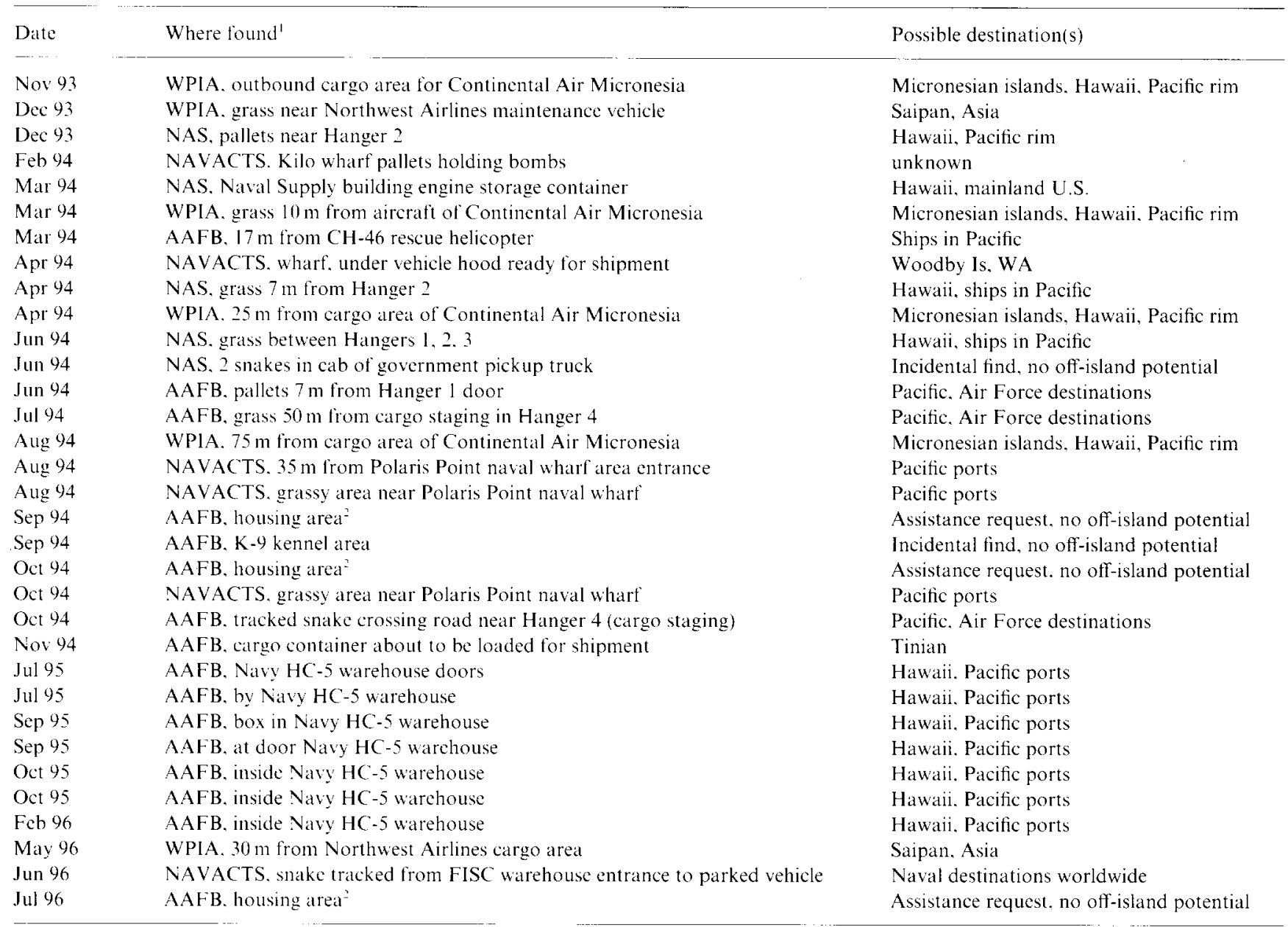

${ }^{1} \mathrm{AAFB}=$ Andersen Air Force Base. FISC = Fleet Industrial and Supply Center. HC-5 = helicopter squadron warehouse (scheduled for closure 8:96), NAS = Naval Air Station (Turned over to Guam Airport Authority in 1995), NAVACTS = Naval Activities, WPIA = Won Pat International Airport.

'The K-9 unit has responded to calls for assistance when brown tree snakes have been spotted around homes. However, searches of household goods prior to off-island moves form an important aspect of the canine program.

assign frequencies of snake discoveries to the categories in Table 1. We can describe the general situations in which snakes were found according to the potential for their export.

Of the snakes found. 4 were in outbound cargo or cargo containers, 6 were found indoors in cargo staging areas immediately accessible to cargo or the transport vessel and 18 were found in the areas immediately outside cargo staging areas. Twenty-one percent (7) of the snakes were found at the HC-5 warehouse on AAFB, a facility located adjacent to a favorable snake habitat. The functions of this warehouse were scheduled to be moved in August 1996 to a central, more developed area of AAFB. As a result, the associated activities should be less susceptible to snake intrusions.

Not all snakes were found as the result of inspection of cargo or vessels awaiting departure from Guam. Three snakes were found by dogs in transit incidental to inspections and 3 others were found at the request of people housed on AAFB after a sighting of a snake in or around their homes

It is impossible to determine with certainty the exact potential destination of all snakes detected because cargo storage areas, the cargo containers, and the vessels carrying the cargo often represent more than one potential destination. However, based on knowledge of cargo flows and the specifics of each case, we produced the most probable destinations in Table 2, if the snakes had been able to successfully depart Guam from the position in which they were detected. Thus, for many of the snakes found, more than one destination is listed in Table 2. Hawaii was the potential destination most frequently 
identified ( 23 of the cases). followed in frequency by 17 cases that could, potentially. have gone to other islands in Micronesia. Because the commercial airlines and military air- and sea-craft travel throughout the Pacific (and the rest of the world), the dog teams are addressing the potential that exists for distributing brown tree snakes to distant areas.

\section{Discussion}

Had the brown tree snakes discovered by the detector dogs managed to be exported, their most likely destinations would have been among the more vulnerable for colonization (Fritts, 1988). The most frequent possible destinations for the snakes detected by the dogs have been Hawaii and the Micronesian islands. however, the entire Pacific rim and mainland U.S. would be potential destinations due to the extensive transportation of cargo there from Guam.

A combination of factors ensured that the bulk of snakes discovered by the dog teams would be in position to travel to vulnerable destinations. Firstly. due to Guam's location. it is very likely that both military and commercial vessels that leave Guam will be destined for, or stop at, other vulnerable Pacific islands. Secondly, detector dog inspections, and control efforts in general, have been directed towards preventing brown tree snakes from becoming stowaways in cargo or vessels going to locations most susceptible to their introduction. Thus. based on the transportation information currently available at the time, dog searches have been emphasized in areas where the potential has been greatest for vessels and cargo to depart for vulnerable destinations.

The detector dog program has developed from the original $2 \mathrm{dog}$ handler teams to the 10 now in use. Since the program was begun in 1993, the number of inspections has been increasing and the rate of snake captures per dog has been decreasing. This is very likely due to the implementation and maintenance of trapping programs and spotlight searches of fence lines in the vicinity of airand sea-port areas. Trapping has been demonstrated to be effective for removing brown tree snakes from the fragmented jungle habitat adjacent to port areas (Engeman et al.. 1998a, 1998b) and spotlight searches also remove significant numbers of snakes from these areas (ADC unpublished data). Because of these efforts, it is likely that fewer snäkes are available to invade cargo staging locations from surrounding areas. Snakes, however, can still be transported inside those areas in vehicles or cargo. Locations that have been identified as high risk for contamination of cargo with snakes, such as facilities within the Harmon industrial area where cargo originates and is containerized prior to transport to ports, are being targeted for development of agreements for teams to conduct detector dog inspections and trapping.
In these areas, inspections of cargo and cargo holding areas may result in an increased capture rate of snakes using dogs until enough trapping has been conducted in those areas to deplete snake populations.

Examination of the cases where detector dogs have found snakes clearly demonstrates the immediate potential for human transportation activity to bring about further dispersal of brown tree snakes. A variety of control methods and strategies for control of brown tree snakes are effective and available (e.g.. Engeman et al., 1998a, 1998b; Linnell et al., 1997), while others are being identified and developed (Brooks et al., 1998, 1998; Savarie et al., 1998). The spread of the brown tree snake from Guam is best deterred through an integration of control methods, including dog inspections as a last line of defence for outbound cargo. A study to define the efficacy of the detector dogs is currently underway; however, a thorough understanding of cargo flows from Guam is necessary to make effective use of the dogs (and other control methods) as a deterrent to dispersal. Compilation of cargo transport information. concomitant with risk assessment and coordination of control activities with commercial and military air- and seaport authorities, has evolved significantly (Linnell and Pitzler, 1996). Risk assessment should be further refined by data currently being collected on environmental conditions in vessels and cargo containers as a means of assessing the prospects for snake survival through the most likely transportation avenues. Use of detector dogs to inspect cargo arriving from Guam at major destinations particularly vulnerable to the introduction of the brown tree snake might further reduce the chance of accidental introductions. The prospect of inadvertently dispersing brown tree snakes from Guam will be minimized by maximizing the application of effective control methods to situations presenting a potential for snake export.

\section{Acknowledgements}

M. Fall, R. Bruggers, J. Shivik, P. Egan, H. Bolton and $G$. Rodda provided valuable reviews of the paper. This operational assessment was conducted under funding provided to the U.S. Department of Agriculture Animal and Plant Health Inspection Service/Animal Damage Control by the U.S. Department of Defense under DOD MIPR-064-95, "Operational Control of Brown Tree Snakes in Guam."

\section{References}

Brooks. J.E., Savarie, P.J., Bruggers, R.L., 1998. Toxicity of commercial insecticide aerosol formulations to brown tree snakes. The Snake (in press).

Brooks. J.E., Savarie, P.J., Johnston. J.J., Bruggers, R.L., 1998. Tox- 
icity of pyrethrin pyrethroid fogger products to brown tree snakes (Boiga irregularis) in cargo containers. The Snake (in press).

Engeman, R.M.. Linnell. M.A., Pochop. P.A.. Gamboa, J., 1998a. Substantial reductions of brown tree snake (Boiga irregularis) populations in blocks of land on Guam through operational trapping. International Biodegradation and Biodeterioration (accepted).

Engeman. R.M.. Sayama. S.. Linnell. M.A.. 1998b. Operational utility of perimeter trapping for removing brown tree snakes (Boiga irregularis) from a defined area. The Snake (in press).

Fritts. T.H. 1987. Movements of snakes via cargo in the Pacific region. Elepaio. 47.17 18.

Fritts, T.H.. 1988. The brown tree snake, Boiga irregularis, a threat to Pacific islands. Biological Report 88(31). U.S. Dept. Interior. Fish and Wildlife Service. Washington, D.C. $36 \mathrm{pp}$.

Fritts, T.H., McCoid, M.J.. 1991. Predation by the brown tree snake (Boiga irrequkris) on poultry and other domesticated animals on Guam. Snake. 23, 75-80.

Fritts, T.H., McCoid, M.J.. Haddock. R.L.. 1990. Risks to infants Infants on Guam from bites of the brown tree snake (Boiga irregu(aris). Amer. J. Trop. Med. Hyg. 42, 607-611.

Fritts. T.H.. Scott. N.J.. Savidge. J.A., 1987. Activity of the arboreal brown tree snake (Boiga inregularis) on Guam as determined by electrical outages. Snake. 19,51-58.

Linnell, M.A.. Engeman. R.M.. Pitzler. M.E.. Watten, M.O., Whitehead, G.F.. Miller. R.C.. 1997. An evaluation of two designs of stamped metal trap flaps for use in the operational control of brown tree snakes (Boiga irregularis). The Snake (in press).
Linnell, M.A. Pitzler, M.E., 1996. Summary of Guam's Outbound Cargo Process with Emphasis on Preventing the Spread of the Brown Tree Snake Off-Island. Working Draft Report, LSDA: APHIS Animal Damage Control. Guam District.

McCoid. M.J.. Fritts, T.H.. Campbell. E.W. III.. (1996). A brown tree snake (Colubridae: Boiga irregularis) sighting in Texas Texas J. Sci. 46. 365-368.

McCoid, M.J.. Stinson. D. 1991. Recent snake sightings in the Mariana Islands. 'Elepaio. 51. 36337.

Rodda. G.H., Fritts, T.H., 1992. The impact of the introduction of the colubrid snake, Boiga irregularis, on Guam's lizards. J. Herpetol. 26. 166-174.

Rodda. G.H.. Fritts, T.H.. Conry, P.J.. 1992. Origin and population growth of the brown tree snake. Boiga irregularis, on Guam. Pac. Sci. 46, 46- 57.

Savarie, P.J.. Wood. S., Rodda. G.. Bruggers, R.L., Engeman. R.M.. 1998. Effectiveness of methyl bromide as a cargo fumigant for brown tree snakes (Boiga imegularis). The Snake (in press).

Savidge. J.A. (1987). Extinction of an island forest avifauna by an introduced snake, Ecology. 68, 660 668 .

Wiles. G.J., 1987. The status of fruit bats on Guam. Pac. Sci. 41, $148-$ 157.

Wiles, G.J.. 1987. Current research and future management of Marianas fruit bats (Chiroplert: Pleropodida) on Guam. Australian Mammology. 10. 93-95.

Wiles, G.J., Aguon, C.F.. Davis, G.W.. Grout. D.J., 1995. The status and distribution of endangered animals and plants in northern Guam. Micronesica. 28, 31-49. 